
A R EVIEW
FOOD SCIENCE
RESEARCH JOURNAL
ISSN-0976-1276 - Visit us : www.researchjournal.co.in
Volume $11 \mid$ Issue 2 | October, $2020 \mid$ 207-212
DOI : $10.15740 / \mathrm{HAS} / \mathrm{FSRJ} / 11.1 / 207-212$

\title{
Nutritional module of sea buckthorn
}

\author{
Sweety Kumari and Sujata Pandit Sharma
}

\begin{abstract}
Seabuckthorn is proved to have industrial, medicinal, cosmetic and nutraceutical value. It contains various extravagant chemical compounds which makes it useful as unconventional provenance in the global market. Sea buckthorn berries are prospects provenience of metabolites which comprises vitamins, carotenoids, phytosterols, antioxidants, tannins, organic acids, fatty acids (saturated and unsaturated fatty acids), amino acids (Leucine, Valine and Alanine), sterols and because of these dynamic bio-active phyto-chemicals sea buckthorn plant parts could play a vital role in improving human health. Ithas an extensive diapason of nutritional and medicinal repercussions. Being an ancient crop, sea buckthorn is used as supplements and a nutritive source commercially. Not only in human health, but also have ecological and economic benefits. This review paper consists and deals for the fundamental nutritional attributes of sea buckthorn.
\end{abstract}

Key Words : Seabuckthorn, Bioactive compounds, Metabolites, Functional food, Polyphenol

How to cite this article : Kumari, Sweety and Sharma, Sujata Pandit (2020). Nutritional module of sea buckthorn. Food Sci. Res. J., 11(2): 207-212, DOI : 10.15740/HAS/FSRJ/11.2/207-212.Copyright@ 2020: Hind Agri-Horticultural Society. 